\title{
Waiting in the queue on Hotelling's Main Street
}

\author{
Citation for published version (APA):
}

Peters, H. J. M., Schröder, M. J. W., \& Vermeulen, A. J. (2015). Waiting in the queue on Hotelling's Main Street. Maastricht University, Graduate School of Business and Economics. GSBE Research Memoranda No. 040 https://doi.org/10.26481/umagsb.2015040

\section{Document status and date:}

Published: 01/01/2015

DOI:

10.26481/umagsb.2015040

Document Version:

Publisher's PDF, also known as Version of record

\section{Please check the document version of this publication:}

- A submitted manuscript is the version of the article upon submission and before peer-review. There can be important differences between the submitted version and the official published version of record.

People interested in the research are advised to contact the author for the final version of the publication, or visit the DOI to the publisher's website.

- The final author version and the galley proof are versions of the publication after peer review.

- The final published version features the final layout of the paper including the volume, issue and page numbers.

Link to publication

\footnotetext{
General rights rights.

- You may freely distribute the URL identifying the publication in the public portal. please follow below link for the End User Agreement:

www.umlib.nl/taverne-license

Take down policy

If you believe that this document breaches copyright please contact us at:

repository@maastrichtuniversity.nl

providing details and we will investigate your claim.
}

Copyright and moral rights for the publications made accessible in the public portal are retained by the authors and/or other copyright owners and it is a condition of accessing publications that users recognise and abide by the legal requirements associated with these

- Users may download and print one copy of any publication from the public portal for the purpose of private study or research.

- You may not further distribute the material or use it for any profit-making activity or commercial gain

If the publication is distributed under the terms of Article $25 \mathrm{fa}$ of the Dutch Copyright Act, indicated by the "Taverne" license above, 


\section{Maastricht University}

Hans Peters, Marc Schröder, Dries Vermeulen

Waiting in the queue on Hotelling's Main Street

$\mathrm{RM} / 15 / 040$

\section{GSBE}

Maastricht University School of Business and Economics

Graduate School of Business and Economics

P.O Box 616

NL- 6200 MD Maastricht

The Netherlands 


\title{
Waiting in the queue on Hotelling's Main Street
}

\author{
Hans Peters*, Marc Schröder*, Dries Vermeulen*
}

\begin{abstract}
We consider a variant of Hotelling's location model that was proposed by Kohlberg (1983): when choosing a firm, consumers take travel time and also (expected) waiting time, which again depends on the number of consumers choosing that firm, into consideration. If we assume that firms are symmetric, then we show that a subgame perfect equilibrium exists if there is an even, but small, number of firms and no subgame perfect equilibrium exists if there is an odd, but small, number of firms. Further, we illustrate by means of examples what other subgame perfect equilibria exist if we allow for asymmetric firms.
\end{abstract}

Journal of Economic Literature Classification Nos. C72, D43, R30

\section{Introduction}

The seminal paper of Hotelling (1929) describes a simple model of spatial competition: firms compete for consumers by means of location on an interval. There are many variants of the model, but most of the literature assumes that both the decision of the location as well the choice of the price are strategic. We consider a more basic version in which firms only compete in their choice of location.

Despite its simple structure, payoffs in Hotelling's model turn out to be discontinuous. In order to circumvent this problem Kohlberg (1983) proposed the natural modification in which consumers care about the travel time as well as the (expected) waiting time for service. This additional feature guarantees payoffs to be continuous. We consider a similar setting and obtain the following contributions.

Results. First, Kohlberg (1983) claims that the modified model has no subgame perfect equilibrium if there are more than two symmetric firms. In his analysis he assumes that firms do not locate in the same location in equilibrium. We provide several examples of subgame perfect equilibria in which two of the firms choose an equal location.

Second, we find that for more than three firms the equilibrium locations of the firms are different from the equilibrium locations in the original model. For example, in the original model the outside firms are always paired, whereas in the equilibrium with four or six symmetric firms this is not the case.

Third, an intriguing aspect of Hotelling's original model is the lack of an equilibrium if three firms compete in location. We provide a condition under which a subgame perfect equilibrium exists if we allow the three firms to be sufficiently asymmetric.

*Address: Department of Quantitative Economics, Maastricht University, P.O. Box 616, 6200 MD Maastricht, The Netherlands. Email: m.schroeder@maastrichtuniversity.nl, h.peters@maastrichtuniversity.nl, d.vermeulen@maastrichtuniversity.nl 
Fourth, we provide an example of a subgame perfect equilibrium in which counter intuitively, a less efficient firm obtains a larger market share due to its location.

Related literature. Hotelling's model is primarily used to explain product differentiation or the lack thereof. The original result found by Hotelling (1929) is that in the case of a duopoly, firms want to minimize differentiation. Eaton and Lipsey (1975) extend this analysis to multiple firms and different market structures. They argue that firms have a tendency to create local clusters, and minimum differentiation is just a special case of a local cluster for two firms. The principle of minimum differentiation was criticized by d'Aspremont, Jaskold Gabszewicz, and Thisse (1979) by showing that no pure price equilibrium exists if locations are sufficiently close. They show that under quadratic transportation costs firms want to maximize differentiation. Osborne and Pitchik (1987) characterize a mixed strategy pricing equilibrium for linear transportation costs in which firms have substantial differentiation. Kohlberg (1983) introduces the modification in which consumers take waiting costs into account and claims that no equilibrium exists for more than two firms. Recently, Ahlin and Ahlin (2013) also included the effect of negative network externalities into the framework with strategic prices. They show that in the presence of congestion costs differentiation among duopolists is decreased. Other recent work considers Hotelling games on graphs, for example Pálvölgyi (2011) and Fournier and Scarsini (2014).

The organization of this paper is as follows. Section 2 explains the basic model with linear waiting costs and provides preliminary results. In Section 3, we consider the model with symmetric firms. The section is split into two main parts: an even number of firms and an odd number of firms. Section 4 allows for asymmetric firms.

\section{The model and preliminary results}

Let $N=\{1, \ldots, n\}$ (where $n \geq 2$ ) be the set of firms. Each firm sells a homogeneous product for a fixed price. The goal of each firm is to maximize their market share. We assume that consumers are uniformly distributed on the interval $[0,1]$. Each consumer purchases one product. In order to do so, the consumer has to visit the location of one of the firms and incurs transportation costs. We normalize the cost of travel to 1 per unit distance. In addition, each firm has (expected) waiting costs: the more consumers visit a particular firm, the longer consumers need to wait.

Kohlberg (1983) assumes that the waiting costs of each firm are defined by a strictly increasing continuous function in the number of consumers served. He assumes this function to be the same for each of the firms. We assume that the waiting costs are linear in the proportion of consumers visiting the firm. Moreover, we allow the importance of the waiting costs to differ from firm to firm. An interpretation is that firms might have different speeds with which consumers are served.

The game proceeds in two stages. In the first stage firms simultaneously select a location. Then in the second stage, the consumers (simultaneously) make their purchasing decision based on these locations.

More formally, define $X=[0,1]^{n}$. Let $x=\left(x_{1}, \ldots, x_{n}\right) \in X$ be the vector of locations of the firms. We define a choice function $f: X \times[0,1] \rightarrow N$ that assigns a firm to each consumer for every vector of locations. A strategy profile is a pair $(x, f)$, where $x$ is a vector of locations and $f$ a choice function. 
Given strategy profile $(x, f)$, we define $f_{i}^{-1}(x)=\{z \in[0,1] \mid f(x, z)=i\}$ for all $i \in N{ }^{1}$ For $i \in N$, let $s_{i}(x, f)$ be the Lebesgue measure of the set $f_{i}^{-1}(x)$ and define $s(x, f)=\left(s_{i}(x, f)\right)_{i \in N}$. We refer to $s_{i}(x, f)$ as the market share of firm $i$. The total costs of a consumer at location $z \in[0,1]$ of visiting firm $i \in N$ are

$$
C_{z, i}(x, f)=\left|x_{i}-z\right|+a_{i} \cdot s_{i}(x, f),
$$

where $a_{i} \in \mathbb{R}_{+}$is the latency of firm $i$.

\subsection{Subgame perfect Nash equilibrium}

Definition 2.1. A strategy profile $(x, f)$ is a subgame perfect Nash equilibrium (SPE) if the following two conditions are satisfied:

(i) for all $i \in N, s_{i}(x, f) \geq s_{i}\left(\left(x_{-i}, x_{i}^{\prime}\right), f\right)$ for all $x_{i}^{\prime} \in[0,1] .^{2}$

(ii) for all $x \in X$ and for all $z \in[0,1], C_{z, f(x, z)}(x, f) \leq C_{z, i}(x, f)$ for all $i \in N$.

Kohlberg (1983) shows that if $a_{i}>0$ for all $i \in N$, then for all vectors of locations $x$, there are unique (in terms of measure) market shares that guarantee that $C_{z, f(x, z)}(x, f) \leq C_{z, i}(x, f)$ for all $z \in[0,1]$ and all $i \in N$.

The following example motivates why we focus on the concept of subgame perfect Nash equilibrium.

Example. Assume $N=\{1,2\}, a_{1}=0$ and $a_{2}=1$. See Figure 1.

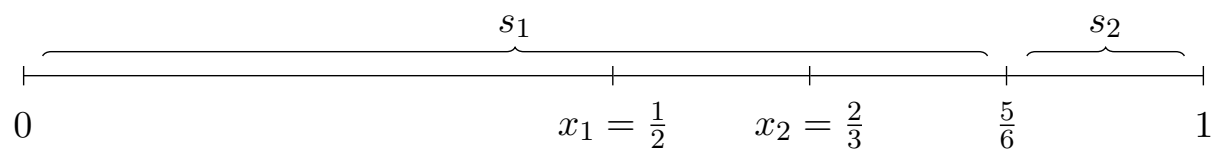

Figure 1: Equilibrium, but no SPE.

Consider the following choice function.

$$
f(x, z)= \begin{cases}1 & \text { if } x_{1}=\frac{1}{2}, x_{2}=\frac{2}{3}, z \leq \frac{5}{6} \\ 2 & \text { if } x_{1}=\frac{1}{2}, x_{2}=\frac{2}{3}, z>\frac{5}{6} \\ 1 & \text { if } x_{1}=\frac{1}{2}, x_{2} \neq \frac{2}{3}, z \in[0,1] \\ 2 & \text { if } x_{1} \neq \frac{1}{2}, x_{2} \in[0,1], z \in[0,1] .\end{cases}
$$

Observe that the strategy profile $(x, f)$ is a Nash equilibrium, neither the firms nor the consumers have an incentive to deviate. However, $(x, f)$ is not an SPE, since condition (ii) in Definition 2.1 does not hold for all $x \in X$.

In fact, for all vectors of locations there is a strategy profile that is a Nash equilibrium. But not every vector of locations is an SPE.

We obtain the following lemma as a result from the behaviour of the consumers.

\footnotetext{
${ }^{1}$ We assume that $f_{i}^{-1}(x)$ is Lebesgue measurable for all $i \in N$.

${ }^{2}$ Define $\left(x_{-i}, x_{i}^{\prime}\right)$ as the vector $\left(x_{1}, \ldots, x_{i-1}, x_{i}^{\prime}, x_{i+1}, \ldots, x_{n}\right)$.
} 
Lemma 2.2. Let $(x, f)$ be an SPE. Then for all $i, j \in N$, with $i \neq j$ and $x_{i} \leq x_{j}$, one of the four following conditions is satisfied.

(i) $x_{i}=x_{j}$ and $C_{z, i}(x, f)=C_{z, j}(x, f)$ for all $z \in[0,1]$.

(ii) $x_{i}<x_{j}$ and $C_{z, i}(x, f)=C_{z, j}(x, f)$ for all $z \in\left[0, x_{i}\right]$ and $C_{z, i}(x, f)>C_{z, j}(x, f)$ for all $z \in\left(x_{i}, 1\right]$.

(iii) $x_{i}<x_{j}$ and $C_{z, i}(x, f)<C_{z, j}(x, f)$ for all $z \in\left[0, x_{j}\right)$ and $C_{z, i}(x, f)=C_{z, j}(x, f)$ for all $z \in\left[x_{j}, 1\right]$.

(iv) $x_{i}<x_{j}$ and there is $y \in\left(x_{i}, x_{j}\right)$ such that $C_{z, i}(x, f)<C_{z, j}(x, f)$ for all $z \in[0, y), C_{y, i}(x, f)=$ $C_{y, j}(x, f)$ and $C_{z, i}(x, f)>C_{z, j}(x, f)$ for all $z \in(y, 1]$.

Proof. (i) Let $x_{i}=x_{j}$. Suppose $a_{i} \cdot s_{i}(x, f) \neq a_{j} \cdot s_{j}(x, f)$. Since $\left|x_{i}-z\right|=\left|x_{j}-z\right|$ for all $z \in[0,1]$, transportation costs are irrelevant. So a consumer visiting the firm with higher queuing costs is better off visiting the firm with lower queuing costs, which contradicts (ii) of Definition 2.1. Hence $C_{z, i}(x, f)=\left|x_{i}-z\right|+a_{i} \cdot s_{i}(x, f)=\left|x_{j}-z\right|+a_{j} \cdot s_{j}(x, f)=C_{z, j}(x, f)$.

(ii) Let $x_{i}<x_{j}$ and $x_{i}+a_{i} \cdot s_{i}(x, f)=x_{j}+a_{j} \cdot s_{j}(x, f)$. Take a consumer $z \in\left[0, x_{i}\right]$ and compare the costs of visiting firm $i$ and $j$. By assumption, $C_{z, i}(x, f)=x_{i}-z+a_{i} \cdot s_{i}(x, f)=$ $x_{j}-z+a_{j} \cdot s_{j}(x, f)=C_{z, j}(x, f)$.

Take a consumer $z \in\left(x_{i}, x_{j}\right]$. Then

$$
C_{z, i}(x, f)=z-x_{i}+a_{i} \cdot s_{i}(x, f)>x_{i}-z+a_{i} \cdot s_{i}(x, f)=x_{j}-z+a_{j} \cdot s_{j}(x, f)=C_{z, j}(x, f),
$$

where the inequality follows from $x_{i}<z$ and the equality from the assumption.

Take a consumer $z \in\left(x_{j}, 1\right]$. Then

$$
\begin{aligned}
C_{z, i}(x, f) & =z-x_{i}+a_{i} \cdot s_{i}(x, f)=z-x_{j}+x_{j}-x_{i}+a_{i} \cdot s_{i}(x, f) \\
& >z-x_{j}+x_{i}-x_{j}+a_{i} \cdot s_{i}(x, f)=z-x_{j}+a_{j} \cdot s_{j}(x, f)=C_{z, j}(x, f),
\end{aligned}
$$

where the inequality follows from $x_{i}<x_{j}$ and the third equality from the assumption.

(iii) Let $x_{i}<x_{j}$ and $x_{j}+a_{i} \cdot s_{i}(x, f)=x_{i}+a_{j} \cdot s_{j}(x, f)$. Then, by symmetry of the problem, a similar argument as for (ii) holds.

(iv) From (ii) and (iii), $C_{x_{i}, i}(x, f) \neq C_{x_{i}, j}(x, f)$ and $C_{x_{j}, i}(x, f) \neq C_{x_{j}, j}(x, f)$.

If $x_{i}$ and $x_{j}$ prefer the same firm, say for example firm $i$. Then all consumers prefer firm $i$ over $j$ and so no consumer will visit firm $j$. However, this is a contradiction as the costs of consumer $x_{j}$ for visiting firm $j$ are 0 , while for firm $i$ strictly positive.

If $C_{x_{i}, i}(x, f)>C_{x_{i}, j}(x, f)$ and $C_{x_{j}, i}(x, f)<C_{x_{j}, j}(x, f)$. Then

$$
a_{i} \cdot s_{i}(x, f)<x_{j}-x_{i}+a_{i} \cdot s_{i}(x, f)<a_{j} \cdot s_{j}(x, f)<x_{j}-x_{i}+a_{j} \cdot s_{j}(x, f)<a_{i} \cdot s_{i}(x, f),
$$

where the first inequality follows from $x_{i}<x_{j}$, the second inequality from $C_{x_{j}, i}(x, f)<C_{x_{j}, j}(x, f)$, the third inequality again from $x_{i}<x_{j}$ and the fourth inequality from $C_{x_{i}, i}(x, f)>C_{x_{i}, j}(x, f)$. Hence also this case results in a contradiction.

So $C_{x_{i}, i}(x, f)<C_{x_{i}, j}(x, f)$ and $C_{x_{j}, i}(x, f)>C_{x_{j}, j}(x, f)$. But then there is $y \in\left(x_{i}, x_{j}\right)$ with $C_{y, i}(x, f)=C_{y, j}(x, f)$. 
Remark. If $(x, f)$ is an SPE, then we assume without loss of generality that $x_{1} \leq \ldots \leq x_{n}$. By Lemma 2.2, if $(x, f)$ is an SPE such that there are consumers $z, z^{\prime}$, with $z<z^{\prime}$ and $f(x, z)>f\left(x, z^{\prime}\right)$, then these consumers are indifferent between the two firms. Hence the assignment of $z$ and $z^{\prime}$ could be interchanged. If we do this in such a way that the market shares are not altered, it is without loss of generality to assume that for a given $x$, consumers $z \in\left[0, s_{1}(x, f)\right)$ visit firm 1 , consumers $z \in\left[s_{1}(x, f), s_{1}(x, f)+s_{2}(x, f)\right)$ visit firm $2, \ldots$, consumers $z \in\left[1-s_{n}(x, f), 1\right]$ visit firm $n$. So in the remainder of this paper, we will only consider these choice functions $f$, and moreover, in the remainder we assume that $f$ satisfies condition (ii) in Definition 2.1 for all $x \in X$.

For each strategy profile $(x, f)$, define $z_{i}(x, f)=\sum_{j=1}^{i} s_{j}(x, f)$ for all $i \in N$, where $z_{0}(x, f)=0$ and $z_{n}(x, f)=1$. The next lemma states that firms go where their consumers are. The result implies that in an SPE, consumers never walk past a firm without visiting that firm.

Lemma 2.3. Let $(x, f)$ be an SPE. Then $x_{i} \in\left[z_{i-1}(x, f), z_{i}(x, f)\right]$.

Proof. Suppose $x_{i} \notin\left[z_{i-1}(x, f), z_{i}(x, f)\right]$. We derive a contradiction by showing that firm $i$ can increase the market share. W.l.o.g see figure below. If multiple firms are located at $x_{i}$, we consider the firm with the lowest subscript.

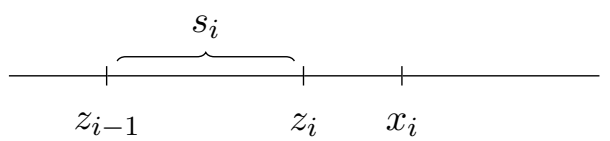

Since $(x, f)$ is an SPE, we have $C_{z_{i-1}(x, f), i-1}(x, f)=C_{z_{i-1}(x, f), i}(x, f)$ and $C_{z_{i}(x, f), i}(x, f)=$ $C_{z_{i}(x, f), i+1}(x, f)$. If firm $i$ locates at $x_{i}^{\prime}$, with $z_{i}(x, f)<x_{i}^{\prime}<x_{i}$, then the transportation costs of each consumer $z \in\left[z_{i-1}(x, f), z_{i}(x, f)\right]$ decrease. Hence $z_{i-1}\left(\left(x_{-i}, x_{i}^{\prime}\right), f\right)$ must shift to the left and $z_{i}\left(\left(x_{-i}, x_{i}^{\prime}\right), f\right)$ must shift to the right such that the decrease in transportation costs is offset by an increase in market share. This however implies $\left.s_{i}\left(\left(x_{-i}, x_{i}^{\prime}\right), f\right)\right)>s_{i}(x, f)$, which contradicts the SPE condition.

Lemma 2.3 has the following two important implications for an SPE.

Lemma 2.4. Let $(x, f)$ be an SPE. Then $x_{1}=s_{1}(x, f)$ and $x_{n}=1-s_{n-1}(x, f)$.

Proof. We show that $x_{1}=s_{1}(x, f)$. Symmetry of the problem implies $x_{n}=1-s_{n-1}(x, f)$.

Suppose $x_{1} \neq s_{1}(x, f)$. Lemma 2.3 implies $x_{1}<s_{1}(x, f) \leq x_{2}$. If firm 1 locates at $x_{1}^{\prime}$, with $x_{1}<x_{1}^{\prime}<s_{1}(x, f)$, we observe from $C_{s_{1}(x, f), 1}(x, f)=C_{s_{1}(x, f), 2}(x, f)$ that $s_{1}(x, f)-x_{1}^{\prime}+a_{1}$. $s_{1}(x, f)<x_{2}-s_{1}(x, f)+a_{2} \cdot s_{2}(x, f)$. So in order to offset the decrease in transportation costs, there must be an increase in the market share of firm 1 . Hence $s_{1}\left(\left(x_{-1}, x_{1}^{\prime}\right), f\right)>s_{1}(x, f)$, which is in contradiction with the SPE condition.

Lemma 2.5. Let $(x, f)$ be an SPE. Then $\left|\left\{i \in N \mid x_{i}=x\right\}\right| \leq 2$ for all $x \in[0,1]$. Moreover, if $x_{i}=x_{i+1}$ for some $i \in N$, then $a_{i}=a_{i+1}$.

Proof. Since $s_{i}(x, f)>0$ for all $i \in N$ in an SPE, Lemma 2.3 implies $\left|\left\{i \in N \mid x_{i}=x\right\}\right| \leq 2$ for all $x \in[0,1]$.

Let $x_{i}=x_{i+1}$ for some $i \in N$. Suppose $a_{i}<a_{i+1}$. We derive a contradiction.

By Lemma 2.3, $x_{i}=x_{i+1}=z_{i}(x, f)$. Define $x^{\prime}=\left(x_{1}, \ldots, x_{i+1}, x_{i}, \ldots, x_{n}\right)$. We obtain the following result. 
Claim. $(x, f)$ is an SPE if and only if $\left(x^{\prime}, f\right)$ is an SPE.

Proof. Suppose $(x, f)$ is an SPE. By Lemma 2.2, we have $C_{z, i}(x, f)=C_{z, i+1}(x, f)$ for all $z \in$ $[0,1]$. So in particular for all $z \in\left[z_{i-1}(x, f), z_{i+1}(x, f)\right]$. Consider the following choice assignment

$$
f\left(x^{\prime}, z\right)= \begin{cases}i+1 & \text { if } z \in\left[z_{i-1}(x, f), z_{i-1}(x, f)+s_{i+1}(x, f)\right] \\ i & \text { if } z \in\left[z_{i-1}(x, f)+s_{i+1}(x, f), z_{i+1}(x, f)\right] . \\ f(x, z) & \text { if } z \in\left[0, z_{i-1}(x, f)\right) \text { or } z \in\left(z_{i+1}(x, f), 1\right] .\end{cases}
$$

So the consumers visiting firm $i+1$ are on the left of the consumers visiting firm $i$. Note that $s_{i}\left(x^{\prime}, f\right)=s_{i}(x, f)$ and $s_{j}\left(x^{\prime}, f\right)=s_{j}(x, f)$ and so $C_{z, i}\left(x^{\prime}, f\right)=C_{z, j}\left(x^{\prime}, f\right)$ for all $z \in$ $\left[z_{i-1}(x, f), z_{i+1}(x, f)\right]$. Since $(x, f)$ is an SPE, $\left(x^{\prime}, f\right)$ is also an SPE.

Since the inverse implication can be proven analogously, this completes the proof of the Claim.

Because $x_{i}=x_{i+1}$, we have $a_{i} \cdot s_{i}(x, f)=a_{i+1} \cdot s_{i+1}(x, f)$ and thus by assumption $s_{i}(x, f)>$ $s_{i+1}(x, f)$. Since $x_{i+1}=z_{i}(x, f)=z_{i-1}(x, f)+s_{i}(x, f)>z_{i-1}(x, f)+s_{i+1}(x, f)$, Lemma 2.3 implies $\left(x^{\prime}, f\right)$ is not an SPE. But then by the above Claim, $(x, f)$ is also no SPE, which implies a contradiction.

\section{Symmetric firms}

Assume that all firms are symmetric, i.e. $a_{i}=a$ for all $i \in N$. Note that if $a=0$ we consider Hotelling's original model and if $a>0$ we consider a special case of Kohlberg's model. Kohlberg (1983) claims that there are no SPE for more than two firms. We reevaluate this claim.

\subsection{Even number of firms}

\subsubsection{Two firms}

Assume $N=\{1,2\}$.

Theorem 3.1. For all $a \geq 0,(x, f)$ is an SPE if and only if $x=\left(\frac{1}{2}, \frac{1}{2}\right)$ and $s(x, f)=\left(\frac{1}{2}, \frac{1}{2}\right)$.

Proof. Let $(x, f)$ be an SPE. Then by Lemma 2.4, $x_{1}=s_{1}(x, f)$ and $x_{2}=1-s_{2}(x, f)$. Since $s_{1}(x, f)+s_{2}(x, f)=1$, we have $x_{1}=x_{2}$. Since $a_{1}=a_{2}=a$, we have $s_{1}(x, f)=s_{2}(x, f)=\frac{1}{2}$ and also $x_{1}=x_{2}=\frac{1}{2}$.

Assume $a_{1}=a_{2}=a$. We show that $x=\left(\frac{1}{2}, \frac{1}{2}\right)$ and $s(x, f)=\left(\frac{1}{2}, \frac{1}{2}\right)$ forms an SPE. Assume $x=\left(\frac{1}{2}, \frac{1}{2}\right)$ and $s(x, f)=\left(\frac{1}{2}, \frac{1}{2}\right)$. Suppose firm 1 locates at $x_{1}^{\prime}<\frac{1}{2}$. Then

$$
s_{1}\left(\left(x_{1}^{\prime}, x_{2}\right), f\right)=\frac{2 x_{1}^{\prime}+1+2 a}{4+4 a} .
$$

Since $\frac{2 x_{1}^{\prime}+1+2 a}{4+4 a}<\frac{1}{2}$ if $x_{1}^{\prime}<\frac{1}{2}$, firm 1 has no profitable deviation to the left. By symmetry of the problem, no deviation is profitable.

Remark. The SPE with symmetric firms is identical to the original equilibrium. 


\subsubsection{Four firms}

Assume $N=\{1,2,3,4\}$.

Theorem 3.2. An SPE exists if and only if (a) $a=0$, or (b) $a \geq 2 \cdot(2+\sqrt{5})$. In case an $S P E$ exists, it is unique.

For $(a)$, the $S P E(x, f)$ is given by $x=\left(\frac{1}{4}, \frac{1}{4}, \frac{3}{4}, \frac{3}{4}\right)$ and $s(x, f)=\left(\frac{1}{4}, \frac{1}{4}, \frac{1}{4}, \frac{1}{4}\right)$.

For $(b)$, the $S P E(x, f)$ is given by $x=\left(\frac{1+a}{2+4 a}, \frac{1}{2}, \frac{1}{2}, \frac{1+3 a}{2+4 a}\right)$ and $s(x, f)=\left(\frac{1+a}{2+4 a}, \frac{a}{2+4 a}, \frac{a}{2+4 a}, \frac{1+a}{2+4 a}\right)$.

Proof. By Eaton and Lipsey (1975), there is a unique SPE if $a=0$. Assume $a>0$. By Lemma 2.5 and symmetry, we distinguish the following four cases.

(1) Assume $x_{1}=x_{2}<x_{3}=x_{4}$. By Lemma 2.4, we obtain the figure below.

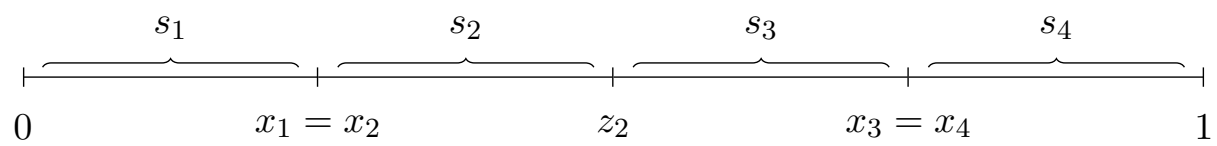

Solving the equalities yields $x=\left(\frac{1}{4}, \frac{1}{4}, \frac{3}{4}, \frac{3}{4}\right)$ and $s(x, f)=\left(\frac{1}{4}, \frac{1}{4}, \frac{1}{4}, \frac{1}{4}\right)$. Suppose firm 2 locates at $x_{2}^{\prime}=\frac{1}{2}$. Then

$$
s_{2}\left(\left(x_{-2}, x_{2}^{\prime}\right), f\right)=\frac{8+15 a+4 a^{2}}{32+56 a+16 a^{2}} .
$$

For this deviation to be unprofitable, we must have $a=0$. This contradicts the assumption that $a>0$.

(2) Assume $x_{1}<x_{2}=x_{3}<x_{4}$. By Lemma 2.3 and Lemma 2.4, we obtain the figure below.

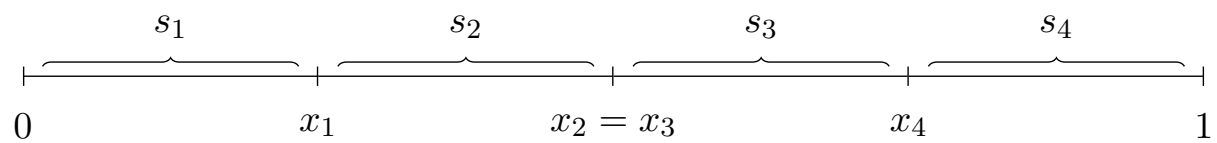

Solving the equalities yields $x=\left(\frac{1+a}{2+4 a}, \frac{1}{2}, \frac{1}{2}, \frac{1+3 a}{2+4 a}\right)$ and $s(x, f)=\left(\frac{1+a}{2+4 a}, \frac{a}{2+4 a}, \frac{a}{2+4 a}, \frac{1+a}{2+4 a}\right)$. Suppose firm 2 locates as leftmost firm at $x_{2}^{\prime}=s_{2}\left(\left(x_{-2}, x_{2}^{\prime}\right), f\right)$. Then

$$
s_{2}\left(\left(x_{-2}, x_{2}^{\prime}\right), f\right)=\frac{(2+a)\left(2+3 a+2 a^{2}\right)}{2\left(4+16 a+17 a^{2}+4 a^{3}\right)} .
$$

For this deviation to be unprofitable, we must have $a \geq 2 \cdot(2+\sqrt{5})$.

To prove that the strategy profile is an SPE, it is sufficient to check that firm 1 does not want to deviate to the right and firm 2 does not want to deviate to the left.

For firm 1. Observe that firm 1 could only improve by being the rightmost firm. Suppose firm 1 locates as rightmost firm at $x_{1}^{\prime}=1-s_{1}\left(\left(x_{-1}, x_{1}^{\prime}\right), f\right)$. Then

$$
s_{1}\left(\left(x_{-1}, x_{1}^{\prime}\right), f\right)=\frac{4+11 a+11 a^{2}+4 a^{3}}{8+38 a+52 a^{2}+16 a^{3}} .
$$

Since $s_{1}\left(\left(x_{-1}, x_{1}^{\prime}\right), f\right)<s_{1}(x, f)$ if $a \geq 2 \cdot(2+\sqrt{5})$, firm 1 has no incentive to deviate. 
For firm 2. Since market shares are piecewise linear in the location of firm 2, we show that firm 2 has no incentive to locate at $x_{2}^{\prime}=x_{1}$ :

$$
s_{2}\left(\left(x_{-2}, x_{2}^{\prime}\right), f\right)=\frac{(2+a)\left(2+5 a+4 a^{2}\right)}{4(1+2 a)\left(4+7 a+2 a^{2}\right)} .
$$

Since $s_{2}\left(\left(x_{-2}, x_{2}^{\prime}\right), f\right)<s_{2}(x, f)$ if $a \geq 2 \cdot(2+\sqrt{5})$, firm 2 has no incentive to deviate. Since there is also no incentive to locate as leftmost firm, firm 2 has no profitable deviation.

(3) Assume $x_{1}=x_{2}<x_{3}<x_{4}$. By Lemma 2.3 and Lemma 2.5, we obtain the figure below. Note that you can show that there is no SPE with $z_{2}(x, f)<x_{3}$.

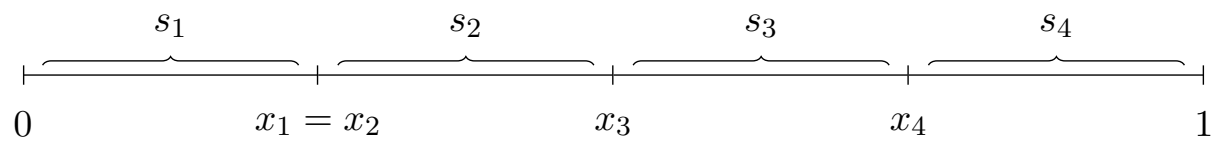

Solving the equalities yields $x=\left(\frac{a^{2}}{1+3 a+4 a^{2}}, \frac{a^{2}}{1+3 a+4 a^{2}}, \frac{2 a^{2}}{1+3 a+4 a^{2}}, \frac{a+3 a^{2}}{1+3 a+4 a^{2}}\right)$ and $s(x, f)=$ $\left(\frac{a^{2}}{1+3 a+4 a^{2}}, \frac{a^{2}}{1+3 a+4 a^{2}}, \frac{a+a^{2}}{1+3 a+4 a^{2}}, \frac{1+2 a+a^{2}}{1+3 a+4 a^{2}}\right)$. Suppose firm 2 locates at $x_{2}^{\prime}=x_{3}$. Then

$$
s_{2}\left(\left(x_{-2}, x_{2}^{\prime}\right), f\right)=\frac{a\left(4+7 a+4 a^{2}\right)}{6+22 a+36 a^{2}+16 a^{3}} .
$$

For this deviation to be unprofitable, we must have $a=0$. However if $a=0$, firm 4 has an incentive to locate at $x_{4}^{\prime}=x_{3}$. Hence there is no SPE.

(4) Suppose $x_{1}<x_{2}<x_{3}<x_{4}$. By Kohlberg (1983), there is no SPE. ${ }^{3}$

Remark. (a) is the original Hotelling equilibrium. (b) are the equilibria with positive latencies, which only exist for sufficiently large $a$. Notice that even though firms are symmetric, their market shares need not be equal.

Example. Let $a=9$. By Theorem 3.2, Figure 2 is the outcome of the SPE.

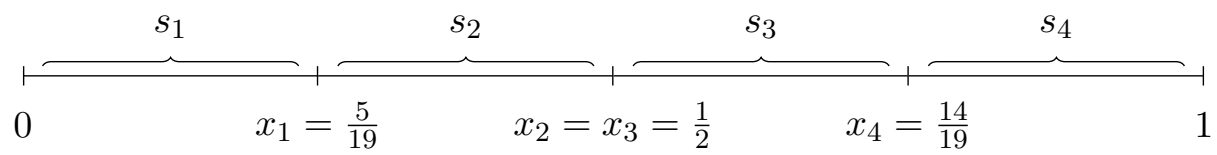

Figure 2: SPE with four symmetric firms.

\subsubsection{Six firms}

Assume $N=\{1,2,3,4,5,6\}$.

Theorem 3.3. An SPE exists if and only if (a) $a=0$, or (b) $a \geq 29.8873^{4}$. In case an SPE exists, it is unique.

For (b), the SPE $(x, f)$ is given by $x=\left(\frac{1+2 a+a^{2}}{2+6 a+6 a^{2}}, \frac{1+3 a+2 a^{2}}{2+6 a+6 a^{2}}, \frac{1}{2}, \frac{1}{2}, \frac{1+3 a+4 a^{2}}{2+6 a+6 a^{2}}, \frac{1+4 a+5 a^{2}}{2+6 a+6 a^{2}}\right)$ and $s(x, f)=\left(\frac{1+2 a+a^{2}}{2+6 a+6 a^{2}}, \frac{a+a^{2}}{2+6 a+6 a^{2}}, \frac{a^{2}}{2+6 a+6 a^{2}}, \frac{a^{2}}{2+6 a+6 a^{2}}, \frac{a+a^{2}}{2+6 a+6 a^{2}}, \frac{1+2 a+a^{2}}{2+6 a+6 a^{2}}\right)$.

\footnotetext{
${ }^{3}$ A proof similar to the previous cases can be used to show the result.

${ }^{4} a$ satisfies the inequality $a^{4}-27 a^{3}-84 a^{2}-68 a-16 \geq 0$
} 
Proof. By Eaton and Lipsey (1975), there are infinitely many SPE if $a=0$. Assume $a>0$. By Lemma 2.5 and symmetry, we distinguish the following nine cases.

(1) Assume $x_{1}=x_{2}<x_{3}=x_{4}<x_{5}=x_{6}$. By Lemma 2.4, we obtain the figure below.

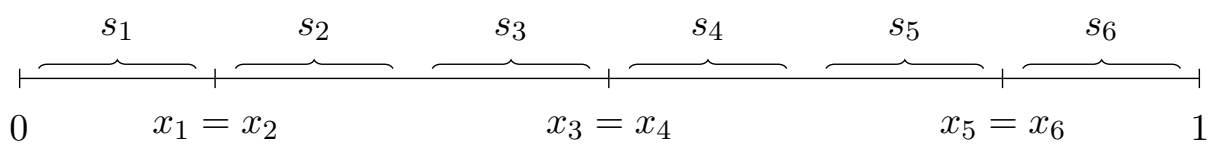

Solving the equalities yields $x=\left(\frac{1}{6}, \frac{1}{6}, \frac{1}{2}, \frac{1}{2}, \frac{5}{6}, \frac{5}{6}\right)$ and $s(x, f)=\left(\frac{1}{6}, \frac{1}{6}, \frac{1}{6}, \frac{1}{6}, \frac{1}{6}, \frac{1}{6}\right)$. Suppose firm 2 locates at $x_{2}^{\prime}=\frac{1}{5}$. Then

$$
s_{2}\left(\left(x_{-2}, x_{2}^{\prime}\right), f\right)=\frac{(8+5 a)\left(20+33 a+6 a^{2}\right)}{60\left(16+36 a+21 a^{2}+3 a^{3}\right)} .
$$

For this deviation to be unprofitable, we must have $a=0$. This contradicts the assumption that $a>0$.

(2) Assume $x_{1}=x_{2}<x_{3}=x_{4}<x_{5}<x_{6}$. By Lemma 2.4, we obtain the figure below. Note that you can show that there is no SPE with $z_{4}(x, f)<x_{5}$.

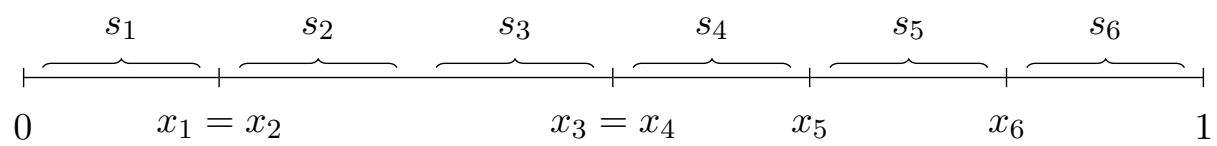

Solving the equalities yields $x=\left(\frac{a^{2}}{1+3 a+6 a^{2}}, \frac{a^{2}}{1+3 a+6 a^{2}}, \frac{3 a^{2}}{1+3 a+6 a^{2}}, \frac{3 a^{2}}{1+3 a+6 a^{2}}, \frac{4 a^{2}}{1+3 a+6 a^{2}}, \frac{a(1+5 a)}{1+3 a+6 a^{2}}\right)$ and $s(x, f)=\left(\frac{a^{2}}{1+3 a+6 a^{2}}, \frac{a^{2}}{1+3 a+6 a^{2}}, \frac{a^{2}}{1+3 a+6 a^{2}}, \frac{a^{2}}{1+3 a+6 a^{2}}, \frac{a(1+a)}{1+3 a+6 a^{2}}, \frac{(1+a)^{2}}{1+3 a+6 a^{2}}\right)$. Suppose firm 2 locates an arbitrary small $\epsilon>0$ to the right. For this deviation to be unprofitable, we must have $a=0$. This contradicts the assumption that $a>0$.

(3) Assume $x_{1}=x_{2}<x_{3}<x_{4}=x_{5}<x_{6}$. By Lemma 2.4, we obtain the figure below. Note that you can show that there is no SPE with $z_{4}(x, f)<x_{5}$.

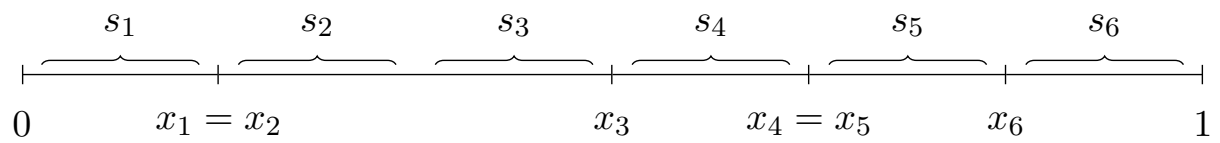

Solving the equalities yields $x=\left(\frac{1+a}{4+6 a}, \frac{1+a}{4+6 a}, \frac{3+3 a}{4+6 a}, \frac{3+4 a}{4+6 a}, \frac{3+4 a}{4+6 a}, \frac{3+5 a}{4+6 a}\right)$ and $s(x, f)=$ $\left(\frac{1+a}{4+6 a}, \frac{1+a}{4+6 a}, \frac{1+a}{4+6 a}, \frac{a}{4+6 a}, \frac{a}{4+6 a}, \frac{1+a}{4+6 a}\right)$. Suppose firm 2 locates an arbitrary small $\epsilon>0$ to the right. For this deviation to be unprofitable, we must have $a=0$. This contradicts the assumption that $a>0$.

(4) Assume $x_{1}=x_{2}<x_{3}<x_{4}<x_{5}=x_{6}$. By Lemma 2.4, we obtain the figure below. Note that you can show that there is no SPE with $z_{2}(x, f)<x_{3}$, or with $z_{4}(x, f)>x_{4}$.

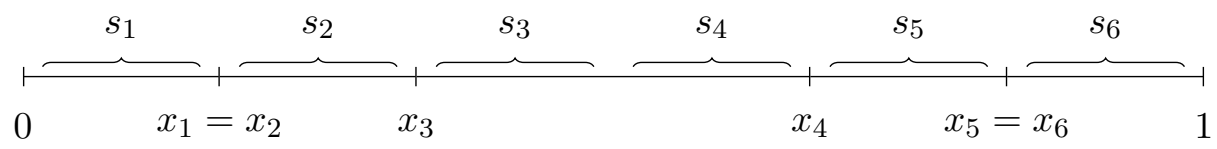


Solving the equalities yields $x=\left(\frac{a}{2+6 a}, \frac{a}{2+6 a}, \frac{2 a}{2+6 a}, \frac{2+4 a}{2+6 a}, \frac{2+5 a}{2+6 a}, \frac{2+5 a}{2+6 a}\right)$ and $s(x, f)=$ $\left(\frac{a}{2+6 a}, \frac{a}{2+6 a}, \frac{1+a}{2+6 a}, \frac{1+a}{2+6 a}, \frac{a}{2+6 a}, \frac{a}{2+6 a}\right)$. Suppose firm 2 locates an arbitrary small $\epsilon>0$ to the right. This deviation is always profitable.

(5) Assume $x_{1}<x_{2}=x_{3}<x_{4}=x_{5}<x_{6}$. By Lemma 2.4, we obtain the figure below.

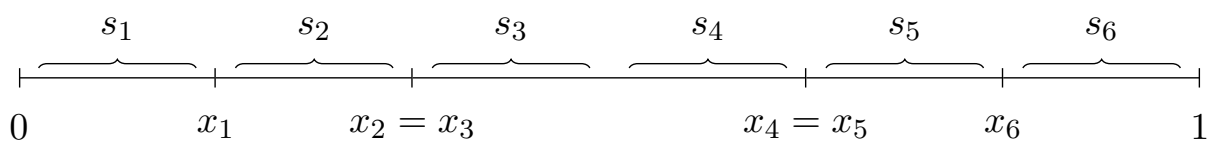

Solving the equalities yields $x=\left(\frac{1+a}{2+6 a}, \frac{1+2 a}{2+6 a}, \frac{1+2 a}{2+6 a}, \frac{1+4 a}{2+6 a}, \frac{1+4 a}{2+6 a}, \frac{1+5 a}{2+6 a}\right)$ and $s(x, f)=$ $\left(\frac{1+a}{2+6 a}, \frac{a}{2+6 a}, \frac{a}{2+6 a}, \frac{a}{2+6 a}, \frac{a}{2+6 a}, \frac{1+a}{2+6 a}\right)$. Suppose firm 2 locates an arbitrary small $\epsilon>0$ to the right. For this deviation to be unprofitable, we must have $a=0$. This contradicts the assumption that $a>0$.

(6) Assume $x_{1}<x_{2}<x_{3}=x_{4}<x_{5}<x_{6}$. By Lemma 2.4, we obtain the figure below.

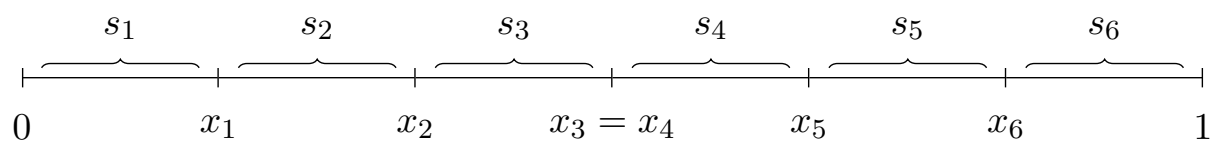

Solving the equalities yields $x=\left(\frac{1+2 a+a^{2}}{2+6 a+6 a^{2}}, \frac{1+3 a+2 a^{2}}{2+6 a+6 a^{2}}, \frac{1}{2}, \frac{1}{2}, \frac{1+3 a+4 a^{2}}{2+6 a+6 a^{2}}, \frac{1+4 a+5 a^{2}}{2+6 a+6 a^{2}}\right)$ and $s(x, f)=$ $\left(\frac{1+2 a+a^{2}}{2+6 a+6 a^{2}}, \frac{a+a^{2}}{2+6 a+6 a^{2}}, \frac{a^{2}}{2+6 a+6 a^{2}}, \frac{a^{2}}{2+6 a+6 a^{2}}, \frac{a+a^{2}}{2+6 a+6 a^{2}}, \frac{1+2 a+a^{2}}{2+6 a+6 a^{2}}\right)$. To prove that the strategy profile is an SPE, it is sufficient to check that firm 1 does not want to deviate to the right, firm 2 does not want to deviate to the left nor the right, and firm 3 does not want to deviate to the left.

For firm 1. Observe that firm 1 could only improve by being the rightmost firm. Suppose firm 1 locates as rightmost firm at $x_{1}^{\prime}=1-s_{1}\left(\left(x_{-1}, x_{1}^{\prime}\right), f\right)$. Then

$$
s_{1}\left(\left(x_{-1}, x_{1}^{\prime}\right), f\right)=\frac{(1+a)^{2}(2+a)(3+2 a)(2+3 a)}{2\left(1+3 a+3 a^{2}\right)\left(12+44 a+39 a^{2}+6 a^{3}\right)} .
$$

Since $s_{1}\left(\left(x_{-1}, x_{1}^{\prime}\right), f\right)<s_{1}(x, f)$ if $a \geq 29.8873$, firm 1 has no incentive to deviate.

For firm 2. Since market shares are piecewise linear in the location of firm 2, we show that firm 2 has no incentive to locate at $x_{2}^{\prime}=x_{1}$ :

$$
s_{2}\left(\left(x_{-2}, x_{2}^{\prime}\right), f\right)=\frac{(1+a)\left(16+56 a+72 a^{2}+39 a^{3}+6 a^{4}\right)}{4\left(1+3 a+3 a^{2}\right)\left(16+36 a+21 a^{2}+3 a^{3}\right)} .
$$

Then we show that firm 2 has no incentive to locate as leftmost firm at $x_{2}^{\prime \prime}=s_{2}\left(\left(x_{-2}, x_{2}^{\prime \prime}\right), f\right)$ :

$$
s_{2}\left(\left(x_{-2}, x_{2}^{\prime \prime}\right), f\right)=\frac{(1+a)\left(16+72 a+124 a^{2}+105 a^{3}+44 a^{4}+6 a^{5}\right)}{4\left(1+3 a+3 a^{2}\right)\left(16+72 a+100 a^{2}+47 a^{3}+6 a^{4}\right)} .
$$

Finally we show that firm 2 has no incentive to locate as rightmost firm at $x_{2}^{\prime \prime \prime}=1-s_{2}\left(\left(x_{-2}, x_{2}^{\prime \prime \prime}\right), f\right)$ :

$$
s_{2}\left(\left(x_{-2}, x_{2}^{\prime \prime \prime}\right), f\right)=\frac{(1+a)\left(16+72 a+124 a^{2}+101 a^{3}+40 a^{4}+6 a^{5}\right)}{2\left(1+3 a+3 a^{2}\right)\left(16+72 a+100 a^{2}+49 a^{3}+6 a^{4}\right)} .
$$


Since $s_{2}\left(\left(x_{-2}, x_{2}^{\prime}\right), f\right)<s_{2}(x, f), s_{2}\left(\left(x_{-2}, x_{2}^{\prime \prime}\right), f\right)<s_{2}(x, f)$ and $s_{2}\left(\left(x_{-2}, x_{2}^{\prime \prime \prime}\right), f\right)<s_{2}(x, f)$ if $a \geq 29.8873$, firm 2 has no incentive to deviate.

For firm 3. Since market shares are piecewise linear in the location of firm 3, we show that firm 3 has no incentive to locate at $x_{3}^{\prime}=x_{2}$ :

$$
s_{3}\left(\left(x_{-3}, x_{3}^{\prime}\right), f\right)=\frac{a(2+3 a)\left(8+18 a+13 a^{2}+2 a^{3}\right)}{4\left(1+3 a+3 a^{2}\right)\left(12+32 a+22 a^{2}+3 a^{3}\right)} .
$$

Then we show that firm 3 has no incentive to locate at $x_{3}^{\prime \prime}=s_{1}\left(\left(x_{-3}, x_{3}^{\prime \prime}\right), f\right)+s_{3}\left(\left(x_{-3}, x_{3}^{\prime \prime}\right), f\right)$ :

$$
s_{3}\left(\left(x_{-3}, x_{3}^{\prime \prime}\right), f\right)=\frac{a\left(16+76 a+132 a^{2}+111 a^{3}+47 a^{4}+6 a^{5}\right)}{4\left(1+3 a+3 a^{2}\right)\left(4+24 a+42 a^{2}+24 a^{3}+3 a^{4}\right)} .
$$

Finally we show that firm 3 has no incentive to locate as leftmost firm at $x_{3}^{\prime \prime}=s_{3}\left(\left(x_{-3}, x_{3}^{\prime \prime}\right), f\right)$ :

$$
s_{3}\left(\left(x_{-3}, x_{3}^{\prime \prime \prime}\right), f\right)=\frac{(1+2 a)\left(4+6 a+a^{2}\right)\left(4+14 a+19 a^{2}+11 a^{3}+3 a^{4}\right)}{2\left(1+3 a+3 a^{2}\right)\left(16+96 a+204 a^{2}+184 a^{3}+65 a^{4}+6 a^{5}\right)} .
$$

Since $s_{3}\left(\left(x_{-3}, x_{3}^{\prime}\right), f\right)<s_{3}(x, f), s_{3}\left(\left(x_{-3}, x_{3}^{\prime \prime}\right), f\right) \leq s_{3}(x, f)$ and $s_{3}\left(\left(x_{-3}, x_{3}^{\prime \prime \prime}\right), f\right)<s_{3}(x, f)$ if $a \geq 29.8873$, firm 3 has no incentive to deviate.

(7) Assume $x_{1}=x_{2}<x_{3}<x_{4}<x_{5}<x_{6}$. By Lemma 2.4, we obtain the figure below. Note that you can show that there is no SPE with $z_{2}(x, f)<x_{3}$, or with $z_{3}(x, f)<x_{4}$, or with $z_{4}(x, f)<x_{5}$.

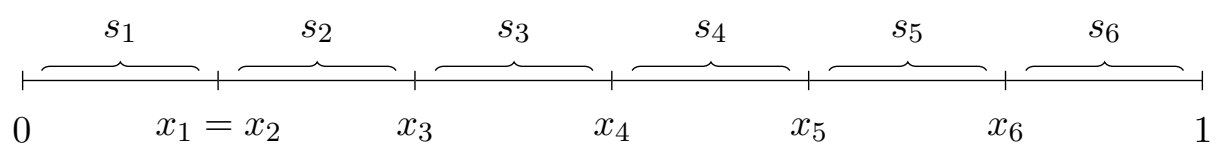

Solving the equalities yields $x=\frac{1}{1+5 a+10 a^{2}+10 a^{3}+6 a^{4}}$.

$\left(a^{4}, a^{4}, 2 a^{4}, a^{3}+3 a^{4}, a^{2}+3 a^{3}+4 a^{4}, a+4 a^{2}+6 a^{3}+5 a^{4}\right)$ and $s(x, f)=\frac{1}{1+5 a+10 a^{2}+10 a^{3}+6 a^{4}}$. $\left(a^{4}, a^{4}, a^{3}(1+a), a^{2}(1+a)^{2}, a(1+a)^{3},(1+a)^{4}\right)$. Suppose firm 2 locates an arbitrary small $\epsilon>0$ to the right. This deviation is always profitable.

(8) Assume $x_{1}<x_{2}=x_{3}<x_{4}<x_{5}<x_{6}$. By Lemma 2.4, we obtain the figure below. Note that you can show that there is no SPE with $z_{3}(x, f)<x_{4}$, or with $z_{4}(x, f)<x_{5}$.

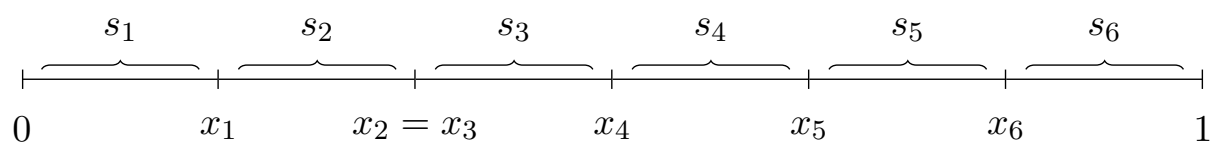

Solving the equalities yields $x=\frac{1}{1+4 a+7 a^{2}+6 a^{3}}$.

$\left(a^{2}+a^{3}, a^{2}+2 a^{3}, a^{2}+2 a^{3}, a^{2}+3 a^{3}, 2 a^{2}+4 a^{3}, a+4 a^{2}+5 a^{3}\right)$ and $s(x, f)=\frac{a^{2}(1+a)}{1+4 a+7 a^{2}+6 a^{3}}$. $\left(a^{2}+a^{3}, a^{3}, a^{3}, a^{2}(1+a), a(1+a)^{2},(1+a)^{3}\right)$. Suppose firm 3 locates an arbitrary small $\epsilon>0$ to the right. This deviation is always profitable.

(9) Suppose $x_{1}<x_{2}<x_{3}<x_{4}<x_{5}<x_{6}$. By Kohlberg (1983), there is no SPE.

Example. Let $a=30$. By Theorem 3.3, Figure 3 is the outcome of the SPE. 


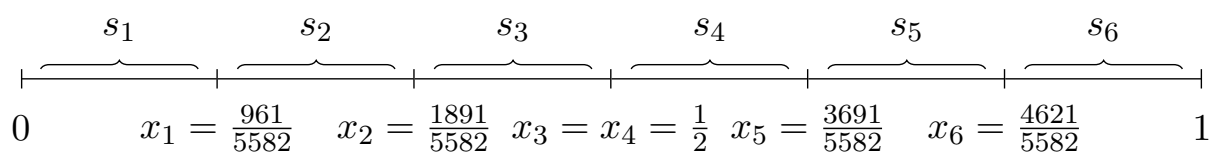

Figure 3: SPE with six symmetric firms

\subsection{Odd number of firms}

\subsubsection{Three firms}

Assume $N=\{1,2,3\}$.

Proposition 3.4. For all $a \geq 0$, there exists no SPE.

Proof. By Lemma 2.5 and symmetry, we distinguish two cases.

(1) Suppose $x_{1}=x_{2}<x_{3}$. Since $a_{1}=a_{2}=a$, we have $s_{1}(x, f)=s_{2}(x, f)$. See figure below.

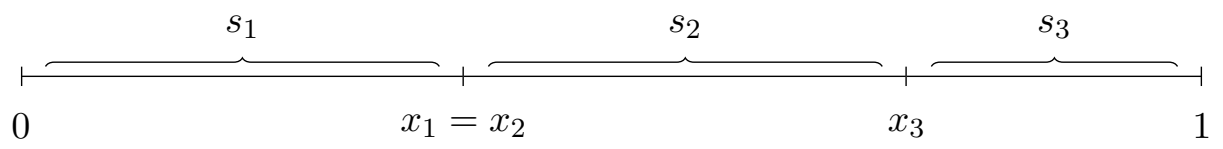

Solving the equalities yields $s(x, f)=\left(\frac{a}{1+3 a}, \frac{a}{1+3 a}, \frac{1+a}{1+3 a}\right)$. Note that $a>0$, since otherwise $s_{1}(x, f)=s_{2}(x, f)=0$ and then both firms could improve by locating at 1 . Suppose firm 2 locates at $x_{2}^{\prime}=x_{3}$. Then

$$
s_{2}\left(\left(x_{-2}, x_{2}^{\prime}\right), f\right)=\frac{2+4 a+3 a^{2}}{(1+3 a)(4+3 a)} .
$$

Since $s_{2}\left(\left(x_{-2}, x_{2}^{\prime}\right), f\right)>s_{2}(x, f)$, firm 2 has an incentive to deviate.

(2) Suppose $x_{1}<x_{2}<x_{3}$. By Kohlberg (1983), there is no SPE.

Remark. Contrary to the case of two firms, there is no SPE when firms are assumed to be symmetric. This is in line with the observation that Hotelling's model with three firms has no equilibrium.

\subsubsection{Five firms}

Assume $N=\{1,2,3,4,5\}$.

Proposition 3.5. For all $a>0$, there exists no SPE.

Proof. Assume $a>0$. By Lemma 2.5 and symmetry, we distinguish the following five cases.

(1) Suppose $x_{1}=x_{2}<x_{3}<x_{4}=x_{5}$. By Lemma 2.3 and Lemma 2.5, we obtain the figure below.

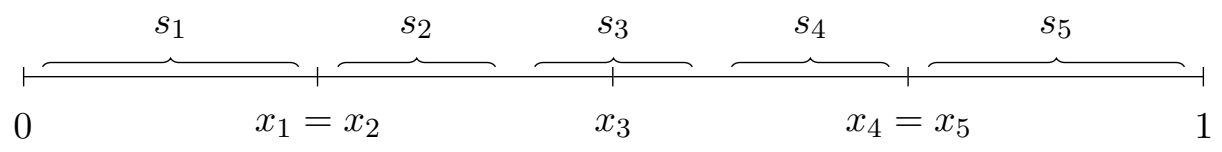


We consider two subcases.

If $z_{2}(x, f)=x_{3}$, then solving the equalities yields $x=\left(\frac{a}{3+5 a}, \frac{a}{3+5 a}, \frac{2 a}{3+5 a}, \frac{2+4 a}{3+5 a}, \frac{2+4 a}{3+5 a}\right)$ and $s(x, f)=\left(\frac{a}{3+5 a}, \frac{a}{3+5 a}, \frac{1+a}{3+5 a}, \frac{1+a}{3+5 a}, \frac{1+a}{3+5 a}\right)$. Suppose firm 2 locates at $x_{2}^{\prime}=x_{3}$. Then

$$
s_{2}\left(\left(x_{-2}, x_{2}^{\prime}\right), f\right)=\frac{a(4+5 a)\left(4+6 a+a^{2}\right)}{(3+5 a)\left(16+44 a+32 a^{2}+5 a^{3}\right)} .
$$

For this deviation to be unprofitable, we must have $a=0$. This contradicts the assumption that $a>0$.

If $z_{2}(x, f)<x_{3}<z_{3}(x, f)$, then solving the equalities yields $x=$ $\left(\frac{(3+5 a) x_{3}+a+a^{2}}{9+18 a+5 a^{2}}, \frac{(3+5 a) x_{3}+a+a^{2}}{9+18 a+5 a^{2}}, x_{3}, \frac{(3+5 a) x_{3}+6+12 a+4 a^{2}}{9+18 a+5 a^{2}}, \frac{(3+5 a) x_{3}+6+12 a+4 a^{2}}{9+18 a+5 a^{2}}\right)$ and $s(x, f)=$ $\left(\frac{(3+5 a) x_{3}+a+a^{2}}{9+18 a+5 a^{2}}, \frac{(3+5 a) x_{3}+a+a^{2}}{9+18 a+5 a^{2}}, \frac{1+a}{3+5 a}, \frac{-(3+5 a) x_{3}+3+6 a+a^{2}}{9+18 a+5 a^{2}}, \frac{-(3+5 a) x_{3}+3+6 a+a^{2}}{9+18 a+5 a^{2}}\right)$. Suppose firm 2 locates at $x_{2}^{\prime}=x_{2}+\epsilon$, where $\epsilon>0$ but arbitrary small. For this deviation to be unprofitable, we must have $a=0$. This contradicts the assumption that $a>0$.

(2) Suppose $x_{1}=x_{2}<x_{3}=x_{4}<x_{5}$. By Lemma 2.3 and Lemma 2.5, we obtain the figure below.

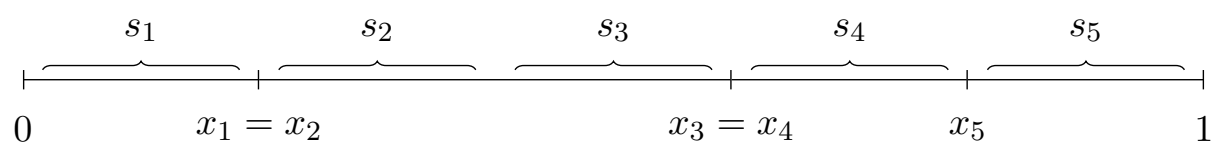

Solving the equalities yields $x=\left(\frac{a}{1+5 a}, \frac{a}{1+5 a}, \frac{3 a}{1+5 a}, \frac{3 a}{1+5 a}, \frac{4 a}{1+5 a}\right)$ and $s(x, f)=$ $\left(\frac{a}{1+5 a}, \frac{a}{1+5 a}, \frac{a}{1+5 a}, \frac{a}{1+5 a}, \frac{1+a}{1+5 a}\right)$. Suppose firm 2 locates at $x_{2}^{\prime}=s_{1}\left(\left(x_{-2}, x_{2}^{\prime}\right), f\right)+s_{2}\left(\left(x_{-2}, x_{2}^{\prime}\right), f\right)$. Then

$$
s_{2}\left(\left(x_{-2}, x_{2}^{\prime}\right), f\right)=\frac{a(2+a)(3+5 a)}{(1+a)(1+5 a)(6+5 a)} .
$$

For this deviation to be unprofitable, we must have $a=0$. This contradicts the assumption that $a>0$.

(3) Suppose $x_{1}<x_{2}=x_{3}<x_{4}<x_{5}$. By Lemma 2.3 and Lemma 2.5, we obtain the figure below.

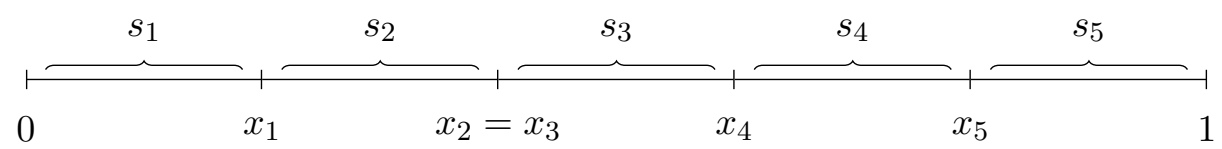

Solving the equalities yields $x=\left(\frac{a+a^{2}}{1+4 a+5 a^{2}}, \frac{a+2 a^{2}}{1+4 a+5 a^{2}}, \frac{a+2 a^{2}}{1+4 a+5 a^{2}}, \frac{a+3 a^{2}}{1+4 a+5 a^{2}}, \frac{2 a+4 a^{2}}{1+4 a+5 a^{2}}\right)$ and $s(x, f)=$ $\left(\frac{a+a^{2}}{1+4 a+5 a^{2}}, \frac{a^{2}}{1+4 a+5 a^{2}}, \frac{a^{2}}{1+4 a+5 a^{2}}, \frac{a+a^{2}}{1+4 a+5 a^{2}}, \frac{1+2 a+a^{2}}{1+4 a+5 a^{2}}\right)$. Suppose firm 3 locates at $x_{3}^{\prime}=x_{4}$. Then

$$
s_{3}\left(\left(x_{-3}, x_{3}^{\prime}\right), f\right)=\frac{a\left(8+22 a+20 a^{2}+5 a^{3}\right)}{\left(1+4 a+5 a^{2}\right)\left(12+20 a+5 a^{2}\right)} .
$$

For this deviation to be unprofitable, we must have $a=0$. This contradicts the assumption that $a>0$. 
(4) Suppose $x_{1}=x_{2}<x_{3}<x_{4}<x_{5}$. By Lemma 2.3 and Lemma 2.5, we obtain the figure below.

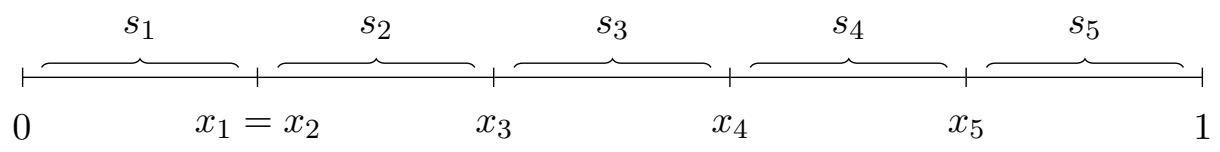

Solving the equalities yields $x=\left(\frac{a^{3}}{1+4 a+6 a^{2}+5 a^{3}}, \frac{a^{3}}{1+4 a+6 a^{2}+5 a^{3}}, \frac{2 a^{3}}{1+4 a+6 a^{2}+5 a^{3}}, \frac{a^{2}+3 a^{3}}{1+4 a+6 a^{2}+5 a^{3}}, \frac{a+3 a^{2}+4 a^{3}}{1+4 a+6 a^{2}+5 a^{3}}\right)$ and $s(x, f)=\left(\frac{a^{3}}{1+4 a+6 a^{2}+5 a^{3}}, \frac{a^{3}}{1+4 a+6 a^{2}+5 a^{3}} \frac{a^{2}+a^{3}}{1+4 a+6 a^{2}+5 a^{3}}, \frac{a+2 a^{2}+a^{3}}{1+4 a+6 a^{2}+5 a^{3}}, \frac{1+3 a+3 a^{2}+a^{3}}{1+4 a+6 a^{2}+5 a^{3}}\right)$. Suppose firm 2 locates at $x_{2}^{\prime}=x_{3}$. Then

$$
s_{2}\left(\left(x_{-2}, x_{2}^{\prime}\right), f\right)=\frac{a^{2}\left(6+10 a+5 a^{2}\right)}{(8+5 a)\left(1+4 a+6 a^{2}+5 a^{3}\right)} .
$$

For this deviation to be unprofitable, we must have $a=0$. This contradicts the assumption that $a>0$.

(5) Suppose $x_{1}<x_{2}<x_{3}<x_{4}<x_{5}$. By Kohlberg (1983), there is no SPE. ${ }^{5}$

\subsection{Discussion}

The above results can be summarized as follows. The results of Hotelling's model are robust for at most three firms, but not for more than three firms. We have seen that there is a unique subgame perfect equilibrium for two firms, independent of the value of $a$, and that there is no subgame perfect equilibrium for three firms, also independent of the value of $a$. However, for more than three firms, we have either discovered new equilibrium locations (for four and six firms) or no equilibria at all (for five firms). This is in contrast to the original results. Unfortunately, there is no general proof for the existence of subgame perfect equilibria that include waiting costs for more than six firms. The conjecture is that existence is guaranteed if the number of firms is even and $a$ sufficiently high, whereas there are no equilibria for an odd number of firms.

\section{General latencies}

In this section, we relax the assumption that all firms are symmetric.

\subsection{Two firms}

Assume $N=\{1,2\}$.

Theorem 4.1. An SPE exists if and only if $a_{1}=a_{2}$.

Proof. Assume an SPE exists. Let $(x, f)$ be an SPE. Then by Lemma 2.4, $x_{1}=s_{1}(x, f)$ and $x_{2}=1-s_{2}(x, f)$. Since $s_{1}(x, f)+s_{2}(x, f)=1$, we have $x_{1}=x_{2}$ and thus by Lemma $2.5, a_{1}=a_{2}$.

Assume $a_{1}=a_{2}$. By Theorem 3.1, $x=\left(\frac{1}{2}, \frac{1}{2}\right)$ and $s(x, f)=\left(\frac{1}{2}, \frac{1}{2}\right)$ forms an SPE.

Remark. There is no SPE if firms are asymmetric.

\footnotetext{
${ }^{5} \mathrm{~A}$ proof similar to the previous cases can be used to show the result.
} 


\subsubsection{Three firms}

Assume $N=\{1,2,3\}$. The first lemma shows that in an SPE it is impossible for all three firms to choose a different location. This is in line with Kohlberg's result.

Lemma 4.2. Let $(x, f)$ be an SPE. Then $x_{1}=x_{2}$ or $x_{2}=x_{3}$.

Proof. Assume $x_{1}<x_{2}<x_{3}$. By Lemma 2.4, we have $x_{1}=s_{1}(x, f)$ and $x_{3}=1-s_{3}(x, f)$. See figure below.

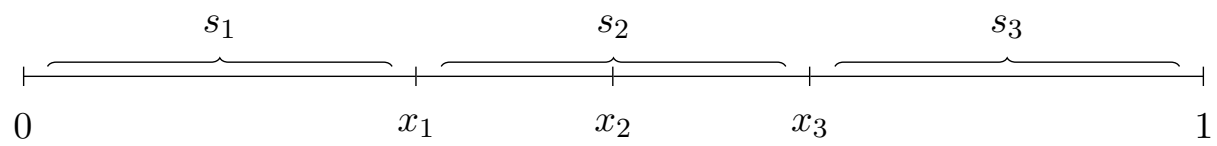

Solving the equalities yields

$$
\begin{aligned}
& s_{1}(x, f)=\frac{\left(1+2 a_{2}+a_{3}\right) x_{2}+a_{2} a_{3}}{1+a_{1}+2 a_{2}+a_{3}+a_{1} a_{2}+a_{1} a_{3}+a_{2} a_{3}}, \\
& s_{2}(x, f)=\frac{\left(a_{1}-a_{3}\right) x_{2}+a_{1} a_{3}+a_{3}}{1+a_{1}+2 a_{2}+a_{3}+a_{1} a_{2}+a_{1} a_{3}+a_{2} a_{3}}, \\
& s_{3}(x, f)=\frac{\left(1+a_{1}+2 a_{2}\right) x_{2}+a_{1} a_{3}+a_{2} a_{3}+a_{3}}{1+a_{1}+2 a_{2}+a_{3}+a_{1} a_{2}+a_{1} a_{3}+a_{2} a_{3}} .
\end{aligned}
$$

Suppose firm 2 locates at $x_{2}^{\prime}=x_{1}$. Then

$$
s_{2}\left(\left(x_{-2}, x_{2}^{\prime}\right), f\right)=\frac{a_{1}\left(\left(2+a_{1}+4 a_{2}+a_{3}\right) x_{2}+a_{3}\left(2+2 a_{1}+4 a_{2}+a_{3}+a_{1} a_{2}+a_{1} a_{3}+a_{2} a_{3}\right)\right)}{\left(1+a_{1}+2 a_{2}+a_{3}+a_{1} a_{2}+a_{1} a_{3}+a_{2} a_{3}\right)\left(2 a_{1}+2 a_{2}+a_{1} a_{2}+a_{1} a_{3}+a_{2} a_{3}\right)} .
$$

Under the assumption that $x_{1}<x_{2}<x_{3}$,

$$
s_{2}(x, f) \geq s_{2}\left(\left(x_{-2}, x_{2}^{\prime}, f\right)\right) \Rightarrow a_{3} \leq a_{1}-2 .
$$

Suppose firm 2 locates at $x_{2}^{\prime \prime}=x_{3}$. Then

$s_{2}\left(\left(x_{-2}, x_{2}^{\prime \prime}, f\right)\right)=\frac{a_{3}\left(-\left(2+a_{1}+4 a_{2}+a_{3}\right) x_{2}+2+3 a_{1}+4 a_{2}+a_{3}+a_{1}^{2}+4 a_{1} a_{2}+2 a_{1} a_{3}+a_{1}^{2} a_{2}+a_{1}^{2} a_{3}+a_{1} a_{2} a_{3}\right)}{\left(1+a_{1}+2 a_{2}+a_{3}+a_{1} a_{2}+a_{1} a_{3}+a_{2} a_{3}\right)\left(2 a_{2}+2 a_{3}+a_{1} a_{2}+a_{1} a_{3}+a_{2} a_{3}\right)}$

Under the assumption that $x_{1}<x_{2}<x_{3}$,

$$
s_{2}(x, f) \geq s_{2}\left(\left(x_{-2}, x_{2}^{\prime \prime}\right), f\right) \Rightarrow a_{3} \geq a_{1}+2 .
$$

Since $a_{3} \leq a_{1}-2$ and $a_{3} \geq a_{1}+2$ are incompatible, firm 2 always has a profitable deviation.

Now we can state the main result of this subsection.

Theorem 4.3. An SPE exists if and only if (a) $a_{1}=a_{2}$ and $a_{3} \geq a_{2}+2$, or (b) $a_{2}=a_{3}$ and $a_{1} \geq a_{2}+2$. In case an $S P E$ exists, it is unique.

For $(a)$, the $S P E(x, f)$ is given by $x=\left(\frac{a_{3}}{1+a_{2}+2 a_{3}}, \frac{a_{3}}{1+a_{2}+2 a_{3}}, \frac{2 a_{3}}{1+a_{2}+2 a_{3}}\right)$ and $s(x, f)=\left(\frac{a_{3}}{1+a_{2}+2 a_{3}}, \frac{a_{3}}{1+a_{2}+2 a_{3}}, \frac{1+a_{2}}{1+a_{2}+2 a_{3}}\right)$.

For $(b)$, the SPE $(x, f)$ is given by $x=\left(\frac{1+a_{2}}{1+2 a_{1}+a_{2}}, \frac{1+a_{1}+a_{2}}{1+2 a_{1}+a_{2}}, \frac{1+a_{1}+a_{2}}{1+2 a_{1}+a_{2}}\right)$ and $s(x, f)=\left(\frac{1+a_{2}}{1+2 a_{1}+a_{2}}, \frac{a_{1}}{1+2 a_{1}+a_{2}}, \frac{a_{1}}{1+2 a_{1}+a_{2}}\right)$. 
Proof. Let $(x, f)$ be an SPE. By Lemma 2.4, we have $x_{1}=s_{1}(x, f)$ and $x_{3}=1-s_{3}(x, f)$. Lemma 4.2 implies $x_{1}=x_{2}$ or $x_{2}=x_{3}$. We show the analysis for $x_{1}=x_{2}$. A symmetric argument can be completed for $x_{2}=x_{3}$.

Let $x_{1}=x_{2}$. By Lemma 2.5, we have $a_{1}=a_{2}$ and thus $s_{1}(x, f)=s_{2}(x, f)$. See figure below.

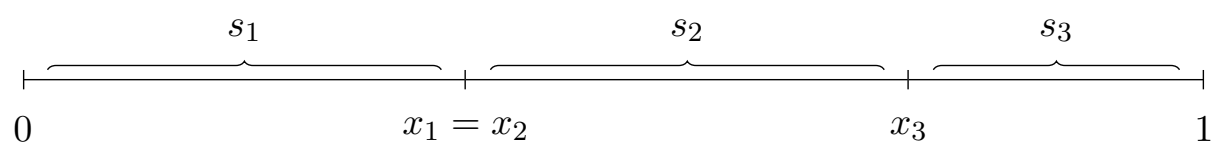

Solving the equalities yields

$$
\begin{aligned}
& s_{1}(x, f)=s_{2}(x, f)=\frac{a_{3}}{1+a_{2}+2 a_{3}}, \\
& s_{3}(x, f)=\frac{1+a_{2}}{1+a_{2}+2 a_{3}} .
\end{aligned}
$$

Note that $a_{3}>0$, since otherwise $s_{1}(x, f)=s_{2}(x, f)=0$ and then both firms could improve by locating at 1.

Suppose firm 2 locates at $x_{2}^{\prime}=x_{3}$. Then

$$
s_{2}\left(\left(x_{-2}, x_{2}^{\prime}\right), f\right)=\frac{a_{3}\left(2+3 a_{2}+a_{3}+a_{2}^{2}+2 a_{2} a_{3}\right)}{\left(1+a_{2}+2 a_{3}\right)\left(2 a_{2}+2 a_{3}+a_{2}^{2}+2 a_{2} a_{3}\right)} .
$$

So

$$
s_{2}(x, f) \geq s_{2}\left(\left(x_{-2}, x_{2}^{\prime}\right), f\right) \Rightarrow a_{3} \geq a_{2}+2 .
$$

To prove that the strategy profile is an SPE, it is sufficient to check that firm 2 does not want to deviate to the right, and firm 3 does not want to deviate to the left.

For firm 2. Since market shares are piecewise linear in the location of firm 2 , firm 2 has no incentive to locate at $x_{2}^{\prime}$, with $x_{2}<x_{2}^{\prime} \leq x_{3}$. Since $1-s_{2}\left(\left(x_{-2}, x_{2}^{\prime}\right), f\right)<x_{3}$ if $x_{2}^{\prime}=x_{3}$, there is also no incentive for firm 2 to locate as the rightmost firm.

For firm 3. Observe that firm 3 could only improve by being the leftmost firm. Suppose firm 3 locates as leftmost firm at $x_{3}^{\prime}=s_{3}\left(\left(x_{-3}, x_{3}^{\prime}\right), f\right)$. Then

$$
s_{3}\left(\left(x_{-3}, x_{3}^{\prime}\right), f\right)=\frac{\left(1+a_{2}\right)\left(a_{2}+2 a_{3}\right)}{\left(1+a_{2}+2 a_{3}\right)\left(2+a_{2}+2 a_{3}\right)} .
$$

Since $s_{3}\left(\left(x_{-3}, x_{3}^{\prime}\right), f\right)<s_{3}(x, f)$ if $a_{3} \geq a_{2}+2$, firm 3 has no incentive to deviate.

Hence the strategy profile is an SPE.

Remark. (1) Contrary to the case of two firms, there is an SPE if firms are asymmetric. (2) If all latencies are sufficiently small, then there exists no SPE (since either $a_{1} \geq a_{2}+2$ or $a_{3} \geq a_{2}+2$ ).

Example. Let $a_{1}=a_{2}=0$ and $a_{3}=2$. By Theorem 4.3, Figure 4 is the outcome of the SPE.

$\overbrace{0}^{s_{1}} \overbrace{x_{1}=x_{2}=\frac{2}{5}}^{s_{2}} \overbrace{x_{3}=\frac{4}{5}}^{s_{3}} 1$

Figure 4: SPE with three firms. 


\subsection{Four firms}

Assume $N=\{1,2,3,4\}$. The following example displays an equilibrium in which there is a firm that is less efficient than another firm, while obtaining a larger market share. The example also shows that there exist different subgame perfect equilibria if we allow firms to be asymmetric.

Example. Let $a_{1}=a_{2}=0, a_{3}=3 \frac{2}{3}$ and $a_{4}=4 \frac{2}{5}$. Figure 5 is the outcome of the strategy profile $(x, f)$. Notice that $s_{3}(x, f)=\frac{33}{310}<\frac{7}{62}=s_{4}(x, f)$.

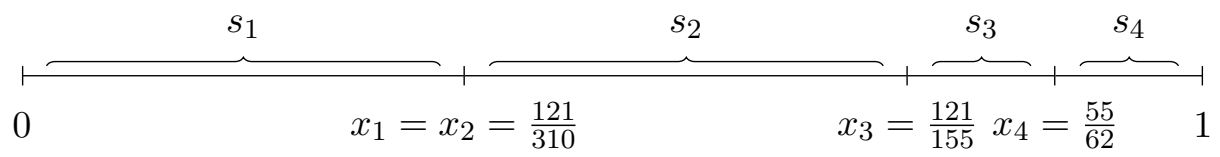

Figure 5: SPE with four asymmetric firms.

Solving the equalities yields $x=\left(\frac{121}{310}, \frac{121}{310}, \frac{121}{155}, \frac{55}{62}\right)$ and $s(x, f)=\left(\frac{121}{310}, \frac{121}{310}, \frac{33}{310}, \frac{7}{62}\right)$. To prove that the strategy profile is an SPE, it is sufficient to check that firm 2 does not want to deviate to the right, firm 3 does not want to deviate to the left nor to the right, and firm 4 does not want to deviate to the left.

For firm 2. Since market shares are piecewise linear in the location of firm 2, we show that firm 2 has no incentive to locate at $x_{2}^{\prime}=x_{3}: s_{2}\left(\left(x_{-2}, x_{2}^{\prime}\right), f\right)=\frac{121}{310}$. Then we show that firm 2 has no incentive to locate at $x_{2}^{\prime \prime}=x_{4}: s_{2}\left(\left(x_{-2}, x_{2}^{\prime \prime}\right), f\right)=\frac{103}{310}$. Since $1-\frac{103}{310}<\frac{55}{62}$, there is also no incentive to locate as rightmost firm.

For firm 3. Observe that firm 3 could only improve by being the leftmost or rightmost firm. Suppose firm 3 locates as leftmost firm at $x_{3}^{\prime}=s_{3}\left(\left(x_{-3}, x_{3}^{\prime}\right), f\right)$. Then $s_{3}\left(\left(x_{-3}, x_{3}^{\prime}\right), f\right)=\frac{363}{4340}$. Suppose firm 3 locates as rightmost firm at $x_{3}^{\prime \prime}=1-s_{3}\left(\left(x_{-3}, x_{3}^{\prime \prime}\right), f\right)$. Then $s_{3}\left(\left(x_{-3}, x_{3}^{\prime}\right), f\right)=\frac{2268}{22475}$. Since $s_{3}\left(\left(x_{-3}, x_{3}^{\prime}\right), f\right)<s_{3}(x, f)$ and $s_{3}\left(\left(x_{-3}, x_{3}^{\prime \prime}\right), f\right)<s_{3}(x, f)$, firm 3 has no incentive to deviate.

For firm 3. Observe that firm 4 could only improve by being the leftmost firm. Suppose firm 4 locates as leftmost firm at $x_{4}^{\prime}=s_{4}\left(\left(x_{-4}, x_{4}^{\prime}\right), f\right)$. Then $s_{4}\left(\left(x_{-4}, x_{4}^{\prime}\right), f\right)=\frac{121}{1674}$. Since $s_{4}\left(\left(x_{-4}, x_{4}^{\prime}\right), f\right)<s_{4}(x, f)$, firm 4 has no incentive to deviate.

\subsection{Discussion}

The last two examples show that the set of equilibria increases if we allow firms the be sufficiently asymmetric. So instead of asking the question whether equilibria exist, it seems more appropriate to ask how they look like. From our results it is clear that a variety of (interesting) equilibria exist in the model with linear latencies. However, a full characterization remains an open question.

\section{References}

Ahlin, C. and Ahlin, P. (2013) Product differentiation under congestion: Hotelling was right. Economic Inquiry 51, 1750-1763.

D'Aspremont, C., Jaskold Gabszewicz, J., and Thisse, J.-F. (1979) On Hotelling's "stability in competition". Econometrica 47, 1145-1150. 
EAton, B. and Lipsey, R. (1975) The principle of minimum differentiation reconsidered: some new developments in the theory of spatial competition. The Review of Economic Studies 42, $27-49$.

Fournier, G. and Scarsini, M. (2014) Hotelling games on networks: efficiency of equilibria. Documents de travail du Centre d'Economie de la Sorbonne 2014.33.

Hotelling, H. (1929) Stability in competition. The Economic Journal 39, 41-57.

KohlBerg, E. (1983) Equilibrium store locations when consumers minimize travel time plus waiting time. Economics Letters 11, 211-216.

Osborne, M. and Pitchik, C. (1987) Equilibrium in Hotelling's model of spatial competition. Econometrica 55, 911-922.

PÁlvÖlgYi, D. (2011) Hotelling on graphs. Mimeo. 